\title{
Value of routine intravenous pyelography in the investigation of hypertension
}

\author{
M. J. FAIRMAN \\ M.B., M.R.C.P.*
}

\author{
J. E. HARPUR \\ M.B., B.S.
}

\author{
M. HAMILTON \\ M.D., F.R.C.P. \\ Chelmsford Group of Hospitals
}

\section{Introduction}

Bright in 1836 first described the course of chronic nephritis, and Mahomed in 1874 in his Paper entitled 'The Pre-albumenuric Stage of Bright's Disease' drew attention to the association of this disease with high arterial tension. It has since been well established that renal disease of many kinds predisposes to arterial hypertension (Longcope and Winkenweider, 1933; Pickering and Heptinstall, 1953; Wilson and Byrom, 1941 ; Goldblatt, 1938) and so the assessment of renal function is now routine in the management of patients presenting with hypertension. This traditional approach usually includes intravenous pyelography as well as examination of the urine, and estimation of the blood urea. The natural aim of these investigations is to disclose a potentially remediable cause for the hypertension, but with the improvements in medical treatment of hypertension in recent years, there has been less emphasis on surgical correction of renal abnormalities, particularly renal artery stenosis (Rees, 1966; Sheps et al., 1965). In the light of this change of attitude we have reviewed the results of routine intravenous pyelography, in patients presenting with hypertension, to reassess the value of this investigation.

\section{Patients and methods}

The intravenous pyelograms of 333 consecutive unselected hypertensive patients (216 females, 117 males) were reviewed. All the patients were attending a Hypertension Clinic and intravenous pyelography had been performed purely as a routine procedure as part of the investigation of the hypertension in those patients between the ages of 40 and 65 who

* Present appointment: Senior Registrar, St James Hospital, Leeds.

Requests for reprints to: Secretary, Medical Academic Unit, Chelmsford \& Essex Hospital, London Road, Chelmsford, Essex. maintained a casual diastolic standing pressure of at least $110 \mathrm{mmHg}$, and those under the age of 40 who $\infty$ maintained a casual standing diastolic pressure of 은 over $90 \mathrm{mmHg}$. The urine was also examined for the presence of protein, casts, abnormal numbers of epi- $\longrightarrow$ thelial cells, leucocytes, and red blood cells. The co initial blood urea level was also reviewed.

\section{Results}

Fifty-nine $(18 \%)$ of the 333 patients had abnorm intravenous pyelograms. There were thirty-si $\vec{x}^{2}$ females and twenty-three males, reflecting the proportion of females to males in the total sample.

Chronic pyelonephritis was the commonest radio- $\frac{\circ}{\Phi}$ logical diagnosis and was seen in thirty-four $(58 \%) \stackrel{2}{\Rightarrow}$ of the cases. The criteria for this diagnosis were blunting of calyces (twenty-eight patients) and/or loss of renal cortex, or cortical scarring (twelve patients). Seven of these showed impaired dye concentration. Appearances suggestive of renal artery stenosis were seen in ten $(17 \%)$ patients. After this came hydronephrosis (seven patients), renal calculi or calcification (six patients), renal cysts (five patients), unilateral non-functioning kidney (four patients), congenital abnormalities (two patients), appearances suggesting tuberculosis (one patient), and retroperitoneal fibrosis (one patient). Some of the patients had more than one abnormality.

These findings are listed in Table 1 , together with $N$ the initial blood urea and urine content. Twenty-one $N$ $(36 \%)$ of the patients with abnormal intravenous pyelograms had a normal blood urea and urine when first seen.

As a result of these findings, certain of the patients underwent further investigation, and in some of these the subsequent treatment was modified in view of the pyelographic appearances. This information is contained in Table 2 alongside the subsequent effect on control over the hypertension. Thus eight patients 
TABLE 1. Type of renal abnormality, initial blood urea and urinalysis

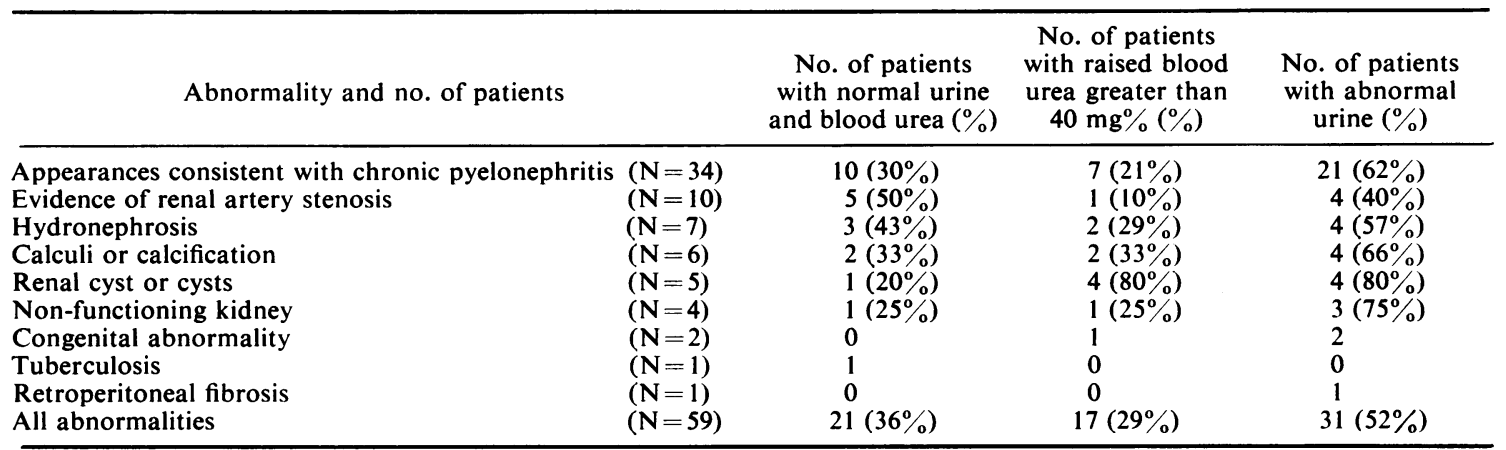

TABLE 2. Action taken as result of i.v.p. findings and effect on blood pressure

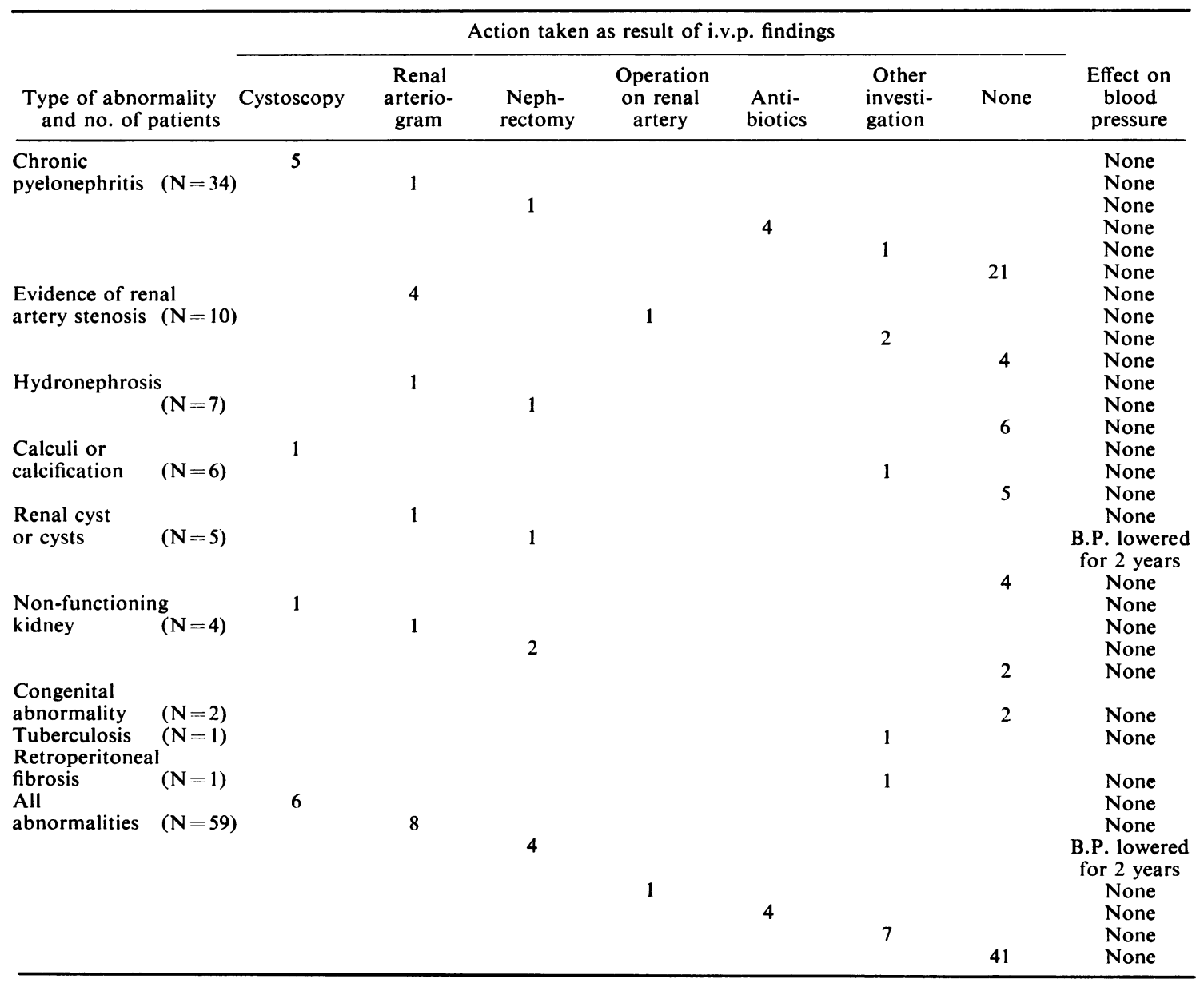


underwent renal arteriography, eight underwent cystoscopy and four patients had a unilateral nephrectomy. One patient with renal artery stenosis was treated surgically. In none of the patients referred for surgical operation was there any permanent lowering effect on the blood pressure, and all of them required continued drug therapy.

\section{Discussion}

The aim of any investigation should be to disclose abnormalities which themselves require treatment, or amend existing or contemplated treatment. In this series there were four patients who required nephrectomy and one who underwent correction of renal artery stenosis but in none of the patients did these procedures result in any permanent reduction of blood pressure making drug control unnecessary. The only benefit in this respect was observed in one patient whose blood pressure returned to normal for 2 years after nephrectomy and then rose to levels requiring treatment.

On the other hand, if the aim of the investigation is to disclose the presence of previously unsuspected renal disease rather than to influence the course of the hypertension, then the intravenous pyelogram assumes greater significance. Thus of 333 patients in the present series, fifty-nine $(18 \%)$ were shown to have a renal abnormality which in four unquestionably demanded nephrectomy and which in the remaining fifty-five might conceivably lead to some impairment of renal function.

Unfortunately, as twenty-one $(36 \%)$ of these patients showed neither a raised blood urea nor abnormality in the urine, further refinement of the selection of hypertensive patients in an attempt to increase the yield of abnormal pyelograms is unrewarding.

We conclude that the value of routine intravenous pyelography in these patients lies in the disclosure of incidental renal disease rather than in the demonstration of a potentially remediable lesion, which might influence the course of the hypertension.

\section{Acknowledgments}

We wish to thank the Department of Radiology for their co-operation, the Chelmsford Medical Education and Research Trust for financial help, and Mrs Pamela Ruddock for her secretarial work.

\section{References}

Bright, R. (1836) Tabular view of the morbid appearances in 100 cases connected with albuminous urine, with observations. Guy's Hospital Report, 1, 338.

GoldblatT, H. (1938) Experimental hypertension induced by renal ischaemia. Bulletin of the New York Academy of Medicine, 14, 523.

LONGCOPE, W.T. \& WinkenWeider, W.L. (1933) Clinical features of contracted kidney due to pyelonephritis. Bulletin of Johns Hopkins Hospital, 53, 255.

MaHOMED, F.A. (1874) The aetiology of Bright's disease and the pre-albumenuric stage. Medical Chirurgical Transactions, 57, 197.

Pickering, G.W. \& Heptinstall, R.H. (1953) Nephrectom and other treatment for hypertension in pyelonephritis Quarterly Journal of Medicine, N.S., 22, 1.

REES, R.S.O. (1966) Arteriography in hypertension. America Heart Journal, 71, 420.

Sheps, S.G., Osmundson, P.J., Hunt, J.C., Schirger, A. \& FAIRBaiRN, J.F. II (1965) Hypertension and renal artery stenosis. Serial observations on 54 patients treated medically. Clinical Pharmacology and Therapeutics, 6, 700.

Wilson, C. \& BYrom, F.B. (1941) The vicious circle in Bright's disease. Experimental evidence from the hypertensive rat. Quarterly Journal of Medicine, N.S., 10, 65. 